DOI: 10.17805/zpu.2018.1.18

\title{
Экзистенциальная проблематика рассказов Л. Улицкой (на примере цикла «Бедные родственники»)
}

\author{
М. Н. МОТАМЕДНИЯ \\ МАЗАНДАРАНСКИЙ УНИВЕРСИТЕТ, ИРАН
}

Данная статья посвящена размышлениям о проблематике малой прозы современной российской писательницы Л. Улицкой на примере цикла ее рассказов «Бедные родственники» (1993). Исследуются противоречивые и, по мнению автора статьи, весьма спорные представления о так называемой аморальности, безнравственности, чернухе, натурализме и бытописательстве Л. Улицкой.

Анализируется проблематика и своеобразие художественного конфликта рассказов «Бедные родственники», «Генеле-сумочница», «Лялин дом» и др. Отмечается внимание Л. Улицкой к экзистенциальным проблемам человеческого существования: гармонии и дисгармонии, плотского и духовного. Подробно рассматривается картина мира героев, выявляется своеобразие внутренних конфликтов в прозе Улицкой, которые писательница помещает внутри, а не вовне. Развитие сюжета, по сути, лишено открытого противостояния и противоборства, но тем острее и насыщеннее его внутреннее течение в психике персонажей, которые переживают крах мировоззрения. Систему устойчивых представлений своих героев Улицкая подвергает серьезному душевному испытанию, а затем анализирует и истоки душевного кризиса героев, и его смыслообразующую суть.

Исследование позволяет прийти к заключению о том, что проза Улицкой, лишенная заметного морализаторства, вместе с тем основана на глубинных представлениях о моральном и аморальном, живом и мертвом, истинном и ложном. Интерес к субстанциональному и экзистенциальному в прозе Улицкой реализуется через изображение внутреннего конфликта, трагическое столкновение в душе персонажа конфликтующих ценностных систем.

Ключевые слова: Людмила Улицкая; русская литература; современная литература; «Бедные родственники»; малая проза; экзистенциальный конфликт

\section{BВЕАЕНИЕ}

$\mathrm{O}$ бщеизвестно, что конфликт - основная и движущая сила действия, определяющая развитие сюжета. Он выступает в виде коллизии (иногда эти термины трактуются как синонимы), т. е. столкновения или противоборства изображенных в произведении действующих характеров и обстоятельств. Однако анализ цикла «Бедные родственники» (1993) показывает, что конфликт в рассказах современной российской писательницы $\Lambda$. Улицкой лишен остроты реальных столкновений: споров, ссор, тем более физического столкновения (драк). Более того, некоторые описываемые в ее рассказах ситуации, которые имеют потенциально конфликтный характер, в качестве буквально конфликтных не реализуются. Это привлекло внимание автора данной статьи и вызвало его научный интерес, тем более что в критике подобная особенность художественного мира $\Lambda$. Улицкой если и замечена, то трактуется противоречиво, и эти противоречия вызывают резонное стремление их разрешить, в том числе в форме научной дискуссии. Аанная статья является нашим вкладом в научную полемику вокруг обозначенной темы.

\section{ОСНОВНАЯ ЧАСТЬ}

Ограниченный естественными рамками публикации, автор приведет один, но очень показательный пример того противоречия, которое сложилось в литературо- 
ведческой оценке творчества $\Lambda$. Улицкой. Вот что, в частности, пишет $\Lambda$. Куклин. С одной стороны, он, как и многие, отмечает, что «Аюдмила Улицкая, безусловно, одна из лучших», с другой стороны, критик адресует ей упреки в «бытописательстве» и натурализме: «Совсем недавно к такому способу отражения жизни прилагали термин “натурализм"» (Куклин, 2003: 177, 178). По его мнению, творчество $\Lambda$. Улицкой сродни «подробному протоколированию... всех затяжных болезней нашего зараженного и изнуренного общества», тот случай, когда «трудное дело литературы превращается в плетение словес, в изготовлении макраме» (там же: 178-179). Кратко характеризуя героев ее рассказов, критик отмечает: «Она ухитряется собрать нечто схожее с коллекцией уродцев петербургской Кунсткамеры, а по сути - коллекцию “биологических неудачников”...» (там же: 179).

На наш взгляд, $\Lambda$. Куклин подходит к проблеме художественных достоинств прозы $\Lambda$. Улицкой с позиций моральной оценки поведения ее персонажей. Объективную манеру письма, которая свойственна писательнице, $\Lambda$. Куклин оценивает как общую индифферентность современной литературы к проблеме добра и зла: «...как и в жизни мы всегда настойчиво, с большим или меньшим успехом ищем выходов из безвыходных положений, так и в литературе должен присутствовать хотя бы намек на такой выход» (там же: 179). Заинтересованные позицией исследователя, мы в данной статье задаемся вопросом: отсутствует ли таковой «выход» у Улицкой? Более того, мы проблематизируем наше рассуждение вопросом: не может ли само его отсутствие стать выходом, в том числе выходом в плоскость экзистенциального?..

Приведем несколько примеров так называемой бесконфликтности у Улицкой. В цикле рассказов «Бедные родственники» Анна Марковна, хотя и считает Асю полусумасшедшей, однако это не мешает ей встречаться с Асей за чашкой чая (рассказ «Бедные родственники»). Генеле приносит родственникам капусту-провансаль, но хотя некоторые из одариваемых считают, что «знаменитая капуста - чистая отрава... никому не приходило в голову отказаться от приношения» ( «Генелесумочница»); во двор к Бухаре и ее умственно отсталой дочери, больной синдромом Аауна, озлобленные соседи кидают дохлых кошек, но Бухара их убирает, и все ( «Аочь Бухары»). Аишенный остроты конкретных столкновений, художественный конфликт в рассказах $\Lambda$. Улицкой перенесен в область умозрительную, в сферу нравственных понятий, моральных оценок и имеет субстанциональный характер «устойчиъых конфликтных положений, которые мыслятся и воссоздаются неразрешенными в рамках единичных жизненных ситуаций, а то и неразрешимыми в принципе» (Хализев, 2004: 222; курсив источника. - M. М. Н.). Событийная коллизия подменяется смысловой оппозицией.

«В основе внутренней организации элементов текста, как правило, лежит прин-

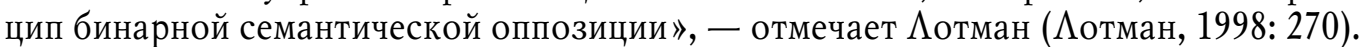
У $\Lambda$. Улицкой бинарная оппозиция часто создается противопоставлением картины мира одного персонажа - картине мира другого. Существует некая модель реальности, свойственная человеку, как правило, обывателю, чья система ценностей или, как говорила писательница в своем интервью, система координат, лишена важных с точки зрения автора ценностей (Улицкая, 2001). Напротив, в мировоззрении и характере другого персонажа («бедного родственника») они присутствуют. На этом основании они противопоставляются. Так, противопоставляются в рассказе «Бед- 
ные родственники» система ценностей Анны Марковны и Аси, в рассказе «Бронька» - система ценностей Броньки и Ирины; в рассказе «Счастливые» противопоставляется общепринятое представление о счастье его авторскому пониманию, наделяющего Матиаса и Берту статусом счастливых. То же самое мы встречаем и в других рассказах цикла. Внешний конфликт заявлен у $\Lambda$. Улицкой как противостояние двух картин мира и их носителей.

При развитии этого конфликта в рассказах конструируются два возможных варианта протекания событий. Первый вариант реализуется в рассказах «Счастливые», «Бедные родственники», «Бронька». Несмотря на то что благополучные герои часто ощущают столкновение собственной системы ценности с системой ценностей бедного родственника (трудность коммуникации Анны Марковны и Аси; Бронька и Ирина расстаются, так и не обменявшись номерами телефонов), конфликт, заявленный в рассказе, не приобретает трагического течения. Бедные и богатые встречаются, ощущают свое несходство во взглядах и с облегчением расстаются - так можно было бы схематически пересказать все перечисленные рассказы. Такой конфликт можно назвать внешним.

Второй вариант демонстрируют рассказы «Аялина квартира», «Генеле-сумочница» и некоторые другие. Конфликт в них выражен в прямом столкновении двух ценностных систем, и это столкновение трагически влияет на судьбу благополучных героинь, нарушает их душевное равновесие, доводит до тяжелого душевного недуга. Такой конфликт назовем внутренним, потому что он локализован в душе одного персонажа. В мягкой форме этот сюжетный вариант реализуется в рассказе «Бронька», где писательница показывает, как повлияла история Броньки на «твердые» и «плотные» представления о жизни Ирины, внучки Анны Марковны: «Ирина Михайловна несла в себе какое-то глубокое и горькое изменение и никак не могла понять, что же произошло... Ее собственная жизнь, и жизнь родителей, и жизнь дочери показались вдруг обесцененными, обесцвеченными... И нелепая, дикая, ничем не объяснимая зависть к Броньке зашевелилась вдруг в ее сердце. Впрочем, всего на одну минуту...» (Улицкая, 2003: 37). Система ценностных координат, носителем которой является Ирина, «обесценилась, обесцветилась», но, поскольку основы ее мировоззрения были затронуты «всего на одну минуту», постольку и душевное спокойствие Ирины осталось неизменно.

В рассказе «Аялин дом» конфликт двух систем ценностей имеет гораздо более драматический характер. $\Lambda$. Улицкая в своих рассказах исследует разные человеческие типы, связывая каждый с той системой ценностных координат, в которой он существует. Своих героев писательница рассматривает как одна из ее героинь (Генеле-сумочница) курицу, которую она выбирает: «Более всего ее манипуляции напоминали серьезный медицинский осмотр... она, казалось, просматривала своим рентгеновским взглядом ее птичью душу» (там же: 43). Примерно в том же положении по отношению к своим персонажам находится $\Lambda$. Улицкая, душевный мир которых она исследует и ставит им диагноз. $\Lambda$. Куклин, подметив нечто подобное, упрекнул писательницу в морально-нравственной индифферентности и негативно определил творчество $\Lambda$. Улицкой как «заполнение больничных карточек»: «...вы приходите в больницу. И все ваши жалобы, недомогания старательно и подробно фиксирует дежурный врач... бесстрастно заполняя больничную карту...» (Куклин, 2003: 178). 
В свое время подобные упреки русская критика обращала А. П. Чехову, писателю «без мировоззрения». $\Lambda$. Улицкая во многом продолжает традиции чеховского письма в изображении человека (Улицкая, 1995: 3). Характер персонажа предстает во всем многообразии свойственных ему личностных особенностей, но лишенный авторского императивного одобрения или порицания. Вместе с тем в подтексте авторская оценка, несомненно, присутствует, о чем $\Lambda$. Улицкая прямо сообщает в своих многочисленных интервью (Улицкая ... : Электронный ресурс).

В рассказе «Иялин дом» таким образом изображается главная героиня $-\Lambda я л я$, семейная женщина, мать двоих детей, живущая легкой жизнью, полной ни к чему не обязывающих любовных приключений. «У которой выходило, что супружеские измены брак только укрепляют, рождают в супругах чувство вины, нежно цементирующее любую трещинку и щербинку в от-

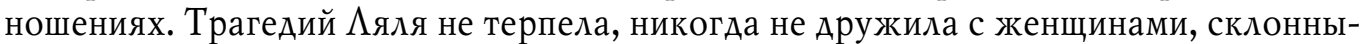
ми к любовным страданиям и романтическому пафосу, и практика жизни убеждала ее в правоте. Ее собственное семейное счастье умножалось на внесемейное...» (Улицкая, 2003: 69).

В рассказе традиционно для $\Lambda$. Улицкой характер героини проясняется посредством пространственной локально-этической метафоры, отраженной в заглавии рассказа - «Иялин дом». Первоначально конфликт оформляется на уровне пространственных категорий. Аялин дом имеет деление на «кабинет» и «кухню». В профессорском кабинете, «откуда раздавался слабый и неритмичный стук пишущей машинки», обитает муж Аяли. Аверь кабинета выполняет функцию границы, отделяющей мир ученого от кухни: «Ему нравилось разноголосье теплой кухни, и красивая моложавая жена, и вся атмосфера вечного предпраздника, но еще больше ему нравилось закрывать за собой дверь и погружаться в нескончаемые и никому не нужные пьесы Тирсо де Молины, которые он переводил всю жизнь...» (Улицкая, 2003: 178). Кухня - Аялино пространство, где вместе с героиней и ее детьми обитает «куча случайного проходного народу, неизвестно где подхваченного» (там же: 70).

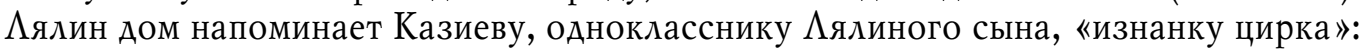
«в этом неряшливом доме постоянно шли разговоры, связанные с общей закулисностью жизни» (там же: 73).

В связи со сравнением с цирком в рассказе возникает мотив переодевания, сбрасывания маски: мать Казиева, «ассистентка своего иллюзорного мужа - иллюзиониста... когда снимала с себя золотое платье и помаду, с большим запасом обводившую тонкогубый рот, обращалась в мымристую нервную блондинку со злыми и несчастными глазами» (там же: 70). Этим подчеркивается, что герои живут праздником, которого нет, что семейное счастье $\Lambda$ яли неполноценно, что дом профессорский дишен истинной духовной связи, объединяющей домочадцев, что тепло, царящее на кухне Аялиного дома, так же иллюзорно, как красота цирковой ассистентки. Иялин дом - это символ ненастоящего, наносного, внешнего, подменяющего истинные ценности. Театрализация мира, население его куклами характерный прием современной прозы, генетически восходящий к художественным принципам В. Набокова (Иеднев, 2006: 122-124).

Населяющие пространство герои внутренне неполноценны, их душевный мир лишен гармоничного сосуществования телесного, умственного и духовного начал. В муже - профессоре, Гоше, $\Lambda$ ене внутренний мир «перекошен» преобладанием 
умственного начала. Ум, лишенный душевного тепла, обращается в отвлеченные умствования: профессор переводит «никому не нужные» пьесы; «причудливо мировоззрением» обладает «христианский социалист» Гоша; Аяля имеет «тонкую теорию брака». В последней, как и в Казиеве, перекос внутреннего мира связан с пре-

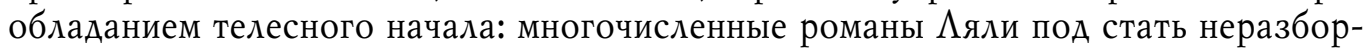
чивости Казиева. Изображение характеров в рассказе служит как бы преамбулой к основному действию.

Завязкой внутреннего конфликта, сосредоточенного в душе Аяли, становится обретенная ею способность страстно любить. Аегковесное отношение к любовным связям, встречам и расставаниям сменяется в героине непреодолимой сосредоточенностью на одном человеке, который заполняет ее душу, страсть подчиняет себе распорядок ее жизни: «...вот настигло ее наказание за всю легкость ее беззаботных любовей, за высокомерную снисходительность к любовному страданию, именно к этой его разновидности, к женской и жадной неутолимости чувств» (Улицкая, 2003: 77).

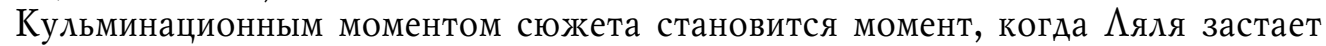
молодого любовника с собственной дочерью. В этот момент в душе героини сталки-

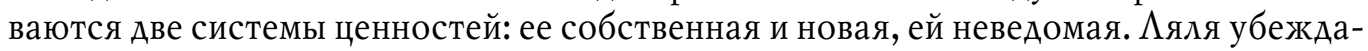
ется, что ее «тонкая теория брака», по которой измены только укрепляют отношения, терпит крах. Оформившийся внутренний конфликт можно определить как противоречие между душевным разбазариванием, плотской неразборчивостью (прошлое героини) и страстной сосредоточенностью на единственном любимом человеке. Общительность Аяли перетекает в острую форму аутизма (такой диагноз предположительно ставят врачи). Но $\Lambda$. Улицкая имеет иное мнение о природе ее болезни и инвалидности и в финале рассказа пишет: «Ее душевная болезнь столь редкая и необычная, что лучшие профессора так и не смогли поставить ей диагноз» (Улицкая, 2003: 82), - объясняется. Видимо, болезнь Аяли имеет не физическую природу, а духовную. Ее возникновение связано с крушением системы ценностных координат, в которой обитает героиня. Внутренний конфликт остается неизжитым и приобретает субстанциональный характер: к Аяле так никогда и не возвращается душевное здоровье.

Система ценностей представлена в художественном мире $\Lambda$. Улицкой образом некоего целого, состоящего из образующих его элементов, находящихся в отношениях строгой детерминированности, жесткости причинно-следственных связей. Метафора «картина мира» в ее рассказах имеет буквальное значение и воплощается как некая когда-то строгая, цельная «картина» (картинка в детской книжке, кирпичная кладка), неожиданно рассыпавшаяся и лишившаяся цельности: «...все словно разбилось на куски и перепуталось. Иногда ей казалось, что... мир снова сложится в правильную, как в детской книжке, картинку. Но усилие это было невозможным. Кирпичная кладка замурованного окна была для нее чрезвычайно привлекательна. Она как будто знала, что именно в трещинах кирпичей, в их простом и правильном, сдвинутом по рядам чередовании есть спасительный порядок, следуя которому можно соединить всю разрушенную картину ее жизни» (там же: 79).

Аналогично описывается крушение мира, которое переживает героиня рассказа $\Lambda$. Улицкой «Генеле-сумочница»: «С Генеле случилось ужасное: весь простой, 
прочный и разумно устроенный мир утратил внутренние связи и стал неузнаваемым... детали... были разрозненны и общей картины не слагалось» (там же: 46). По внешним признакам легко определить, что Генеле пережила инсульт, но $\Lambda$. Улицкая заставляет читателя усомниться в этом. Повествование строится так, что смерть Генеле как будто вытекает из утраты драгоценной сумки. Ведь именно сумка с бриллиантами была средоточием ее жизни и организующим центром ее внутреннего мира: «...мучительная чехарда из бессвязных картинок внутри и снаружи замедлилась, и из нее выплыл один-единственный образ вместе со словом, к нему относящимся. Это была сумка» (там же: 47). Конфликт сконцентрирован в душе героини и определяется как противоречие между земными ценностями и ценностями иного мира, где материальное значит очень мало. Перед смертью «ласковой и печальный голос кого-то знакомого все говорил ей: “Брось, брось, оставь!” Но Генеле не сдалась до конца. Так она и умерла, скрючив левую руку и подогнув пальцы, сжимающие невидимый замок» (там же: 47). «Аасковый и печальный голос», видимо, принадлежит Богу, с которым спорит Генеле и не желает покориться. В итоге она побеждает, поскольку родственники хоронят ее вместе с неразлучной сумкой, и бриллианты навсегда становятся ее неоспоримой собственностью.

Такого типа конфликт характерен и для других рассказов $\Lambda$. Улицкой, вошедших в цикл «Бедные родственники». В центр художественного мира $\Lambda$. Улицкой поставлен человек, его внутренняя духовная сущность. В одном из своих интервью писательница сказала: «...меня интересуют не проблемы, явления, идеи, а собственно человек в соприкосновении с проблемами, идеями и прочим. <..> Если определять направление моего интереса, это - человек...» (Улицкая, 2004: 3).

Изучая человеческую душу, $\Lambda$. Улицкая детально исследует внутренний мир, и при этом ее интерес по большей части сосредоточен на проблеме соотношения в человеке физического (плотского, телесного) и духовного, существа и существования. Часто два этих начала в человеке сосуществуют негармонично, и в этом согласно концепции $\Lambda$. Улицкой главное средоточие человеческой жизни, ее боль и ее смысл. Возникновение внутреннего конфликта в душе человека обусловлено в основном двумя причинами: во-первых, дисбалансом телесного и духовного, когда духовное начало «задавлено» излишним вниманием человека к внешней (материальной или физической) стороне жизни. Например, в уже рассмотренном рассказе «Генеле-сумочница», где героиня «зациклена»на бриллиантах, а также в рассказе «Аялин дом», где беды героини становятся следствием ее повышенного внимания к физической стороне любовных отношений. В последнем (при том что Аяля остается инвалидом) автор своей волей демиурга в художественном мире наказывает и Казиева. Сосредоточенность героя на внешней телесно-сексуальной стороне жизни закономерно обусловливает, что Казиев не смог стать цирковым режиссером, т. е. человеком творческим (ведь творчество - область духовной работы), и в конце концов устроился мясником: «Молодой Казиев... карьеры не сделал. Чтото сломалось в его жизни... Стал учеником мясника в маленьком магазинчике на Трубной, быстро обучился нехитрой мясной науке... и работает по сей день в пахнущем старой кровью подвале» (Улицкая, 2003: 81). Физическая неполноценность «прощается» автором своим героям, но духовная - никогда.

Во-вторых, внутренний конфликт в рассказах $\Lambda$. Улицкой часто определяется как дисгармония духовного и телесного при физической неполноценности челове- 
ка. $\Lambda$. Куклин на этом основании, как мы уже сказали, сравнил персонажную систему рассказов $\Lambda$. Улицкой как с коллекцией уродцев петербургской Кунсткамеры. «Ааунизм и сумасшествие - частые гости на страницах ее рассказов», - пишет он (Куклин, 2003: 81). В. Чалмаев вообще отказал $\Lambda$. Улицкой в нравственности. По его мнению, ее творчество определяется «“чернушным” фоном протекания семейной жизни, грязной грубостью любовных отношений, прямым разрушением... идеалов стыдливости, скромности...» (Чалмаев, 2002: 21).

Однако исследователи как будто не заметили (или не захотели заметить) того, как изображаются эти герои. Напротив, если рассуждать о литературе в категориях моральное / аморальное, $\Lambda$. Улицкая подходит к жизни и человеку с позиций строгой нравственности. Каждый герой в ее рассказах оценивается автором с точки зрения того, насколько гармоничен его внутренний мир и в чем именно выражается замеченная дисгармония, и цикл «Бедные родственники», на наш взгляд, тому очень яркое доказательство.

\section{ЗАКАЮЧЕНИЕ}

Как видим, для малой прозы $\Lambda$. Улицкой характерны своеобразие проблематики, интерес к субстациональному и экзистенциальному, внутренний конфликт, выраженный в прямом столкновении в душе персонажа двух ценностных систем. Последнее трагически влияет на судьбу благополучных героинь, нарушает их душевное равновесие, доводит до тяжелого душевного недуга (например, в рассказе «Аялин дом»).

Изучая человеческую душу, $\Lambda$. Улицкая детально исследует внутренний мир. При этом ее интерес по большей части сосредоточен на проблеме соотношения в человеке телесного начала и духовного. Часто два этих начала в человеке сосуществуют негармонично, создают трагическую дисгармонию плотского и душевного.

Проблематика экзистенциального в рассказах $\Lambda$. Улицкой реализуется в композиционном противопоставлении отдельных ситуаций, предметных деталей, изобразительных ракурсов трагически контрастных картин внутреннего, духовного мироустройства.

\section{СПИСОК АИТЕРАТУРЫ}

Куклин, $\Lambda$. (2003) Казус Улицкой // Нева. № 7. С. 177-183.

$\Lambda$ еденев, А. В. (2006) Между фактом и фикцией: набоковское стилевое влияние в современной женской прозе // Вестник МГУ. Сер. 9. Филология. № 2. С. 112-124.

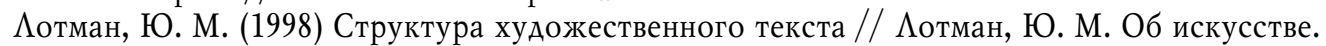
СПб. : Искусство - СПб. С. 14-285.

Улицкая, А. (1995) Мне интересна жизнь «серых людей»... / записала М. Рюрикова // Һитературная газета. № 38. С. 3.

Улицкая, $\Lambda$. (2001) Адюльтер для меня совершенно исключен... // Московский комсомолец. 24 декабря. С. 6.

Улицкая, $\Lambda$. (2003) Бедные, здые, любимые: Повести. Рассказы. М. : Эксмо. 384 с.

Улицкая, $\Lambda$. (2004) «Аля меня самое интересное - человек...»// Книжное обозрение. № 22-23. С. 3.

Улицкая $\Lambda$. Е. - русская писательница и сценарист [Электронный ресурс]// Союз писателей. URL: http://soyuz-pisatelei.ru/forum/57-1166-1 (дата обращения: 20.12.2017). 
Хализев, В. Е. (2004) Теория литературы. М. : Высшая школа. 405 с.

Чалмаев, В. (2002) Русская проза 1980-2000 годов на перекрестке мнений и споров // Аитература в школе. № 4. С. 21.

Аата поступления: 25.12.2017 2.

\section{EXISTENTIAL PROBLEMS OF L. ULITSKAYA'S STORIES \\ (EXEMPLIFIED BY THE CYCLE «POOR RELATIVES») \\ M. N. MOTAMEDNIA \\ UNIVERSITY OF MAZANDARAN, ISLAMIC OF IRAN}

This article is devoted to the reflections on the problems of L. Ulitskaya's small prose exemplified by the cycle of her stories "Poor Relatives" (1993). It studies the contradictory and, in the author's opinion, very controversial ideas of so-called immorality, seamy side, naturalism and the slice of life shown by L. Ulitskaya.

The author of the article analyses the problems and originality of the artistic conflict of the short stories «Poor Relatives», "Genele the Bag Lady», "Lyalya's House», and others. It is noted that L. Ulitskaya's attention is paid to the existential problems of human's living: harmony and disharmony, the carnal and the spiritual. Careful consideration is given to the picture of the characters' world ; the peculiarity of internal conflicts in Ulitskaya's prose is revealed, which the writer puts inside, and not outside. The development of the plot, in fact, is devoid of open confrontation, but it makes its inner course sharper and more intense in the psyche of the characters, who are experiencing a collapse of their worldview. L. Ulitskaya subjects the system of her heroes' strong convictions to a serious spiritual test and then analyses both the origins of the heroes' emotional crisis and its sense-forming essence.

The study allows us to conclude that Ulitskaya's prose is devoid of appreciable moralising, and at the same time is based on profound understanding of the moral and immoral, living and dead, true and false. Interest in the substantial and existential is realised in Ulitskaya's prose through the image of the inner conflict, a tragic clash of the conflicting value systems in the soul of a character.

Keywords: Lyudmila Ulitskaya; Russian literature; modern literature; "Poor Relatives"; small prose; existential conflict

\section{REFERENCES}

Kuklin, L. (2003) Kazus Ulitskoi. Neva, no. 7, pp. 177-183. (In Russ.).

Ledenev, A. V. (2006) Mezhdu faktom i fiktsiei: nabokovskoe stilevoe vliianie v sovremennoi zhenskoi proze. Vestnik MGU, issue 9, Filologiia, no. 2, pp. 112-124. (In Russ.).

Lotman, Iu. M. (1998) Struktura khudozhestvennogo teksta. In: Lotman, Iu. M. Ob iskusstve. St. Petersburg, Iskusstvo - SPb. Pp. 14-285. (In Russ.).

Ulitskaia, L. (1995) Mne interesna zhizn' «serykh liudei».../ M. Riurikova. Literaturnaia gazeta, no. 38, p. 3. (In Russ.).

Ulitskaia, L. (2001) Adiul'ter dlia menia sovershenno iskliuchen... Moskovskii komsomolets, 24 December, p. 6. (In Russ.).

Ulitskaia, L. (2003) Bednye, zlye, liubimye: Povesti. Rasskazy. Moscow, Eksmo. 384 p. (In Russ.).

Ulitskaia, L. (2004) «Dlia menia samoe interesnoe - chelovek...» Knizbnoe obozrenie, no. 22-23, p. 3. (In Russ.).

Ulitskaia L. E. — russkaia pisatel'nitsa i stsenarist. Soiuz pisatelei [online] Available: http://soyuzpisatelei.ru/forum/57-1166-1 (access date: 20.12.2017). (In Russ.).

Khalizev, V. E. (2004) Teoriia literatury. Moscow, Vysshaia shkola. 405 p. (In Russ.).

Chalmaev, V. (2002) Russkaia proza 1980-2000 godov na perekrestke mnenii i sporov. Literatura $v$ shkole, no. 4, p. 21. (In Russ.). 
Мотамедния Масумех Насроллах - кандидат филологических наук, доцент кафедры русского языка Мазандаранского университета, г. Баболсар, Иран. Адрес: Исламская Республика Иран, провинция Мазандаран, г. Баболсар, ул. Пасдаран, 4741613534. Тел.: +98 1135302674 . Эл. aspec:m.motamednia@umz.ac.ir

Motamednia Masoumeh Nasrollah, Candidate of Philology, Associate Professor, Department of Russian Language, University of Mazandaran, Babolsar, Iran. Postal address: Pasdaran St., Babolsar, Mazandaran Province, Islamic Republic of Iran, 4741613534. Tel.: +98 11 35302674. E-mail: m.motamednia@umz.ac.ir 